\title{
BIOMARCADORES CARDÍACOS E SUA APLICABILIDADE CLÍNICA EM CÃES E GATOS
}

Tayanne Gobbi Mendes ${ }^{1}$, Paulo Roberto de Sousa ${ }^{1}$, Rauane Sousa de Moura ${ }^{2}$ Rosângela de Oliveira Alves Carvalho ${ }^{3}$.

1. Mestrando, Programa de Pós-graduação da Escola de Veterinária e Zootecnia da Universidade Federal de Goiás, Goiânia, Brasil. E-mail: taygobbi@hotmail.com.

2. Doutoranda, Programa de Pós-graduação da Escola de Veterinária e Zootecnia da Universidade Federal de Goiás, Goiânia, Brasil

3. Doutora, Docente da Escola de Veterinária e Zootecnia da Universidade Federal de Goiás, Goiânia, Brasil.

Recebido em: 06/04/2019 - Aprovado em: 10/06/2019 - Publicado em: 30/06/2019 DOI: 10.18677/EnciBio_2019A31

Os biomarcadores ou marcadores biológicos são substâncias produzidas e liberadas de um órgão ou tecido, que indicam a ocorrência de uma determinada função, seja ela normal ou patológica. São substâncias que podem ser mensuradas por meio de fluidos corporais e permite a avaliação de certas alterações provocadas a um órgão ou tecido, sendo que o biomarcador ideal deve fornecer informações sobre diagnóstico, prognóstico ou resposta ao tratamento já realizado ao paciente. Este artigo de revisão descreverá sobre a utilidade dos biomarcadores cardíacos de estresse e lesão miocárdica como auxiliares para o diagnóstico e prognóstico das cardiopatias em cães e gatos.

PALAVRAS-CHAVE: biomarcadores, cardiomiócitos, doenças cardíacas.

\section{HEART BIOMARKERS AND THEIR CLINICAL APPLICABILITY IN DOGS AND CATS}

\section{ABSTRACT}

Biomarkers or biological markers are substances produced and released from an organ or tissue, which indicate the occurrence of a certain function, be it normal or pathological. They are substances that can be measured by means of body fluids and allows the evaluation of certain changes caused to an organ or tissue, and the ideal biomarker should provide information about diagnosis, prognosis or response to treatment already performed on the patient. This review article will describe the usefulness of cardiac biomarkers of stress and myocardial injury as aids for the diagnosis and prognosis of heart diseases in dogs and cats. KEYWORDS: biomarkers, cardiomyocytes, heart diseases.

\section{INTRODUÇÃO}

Os biomarcadores ou marcadores biológicos são substâncias que podem ser mensuradas em fluidos corporais e indicam a ocorrência de uma determinada função, normal ou patológica, sendo específicos para o órgão ou tecido em estudo. Essas substâncias são liberadas em proporção a lesões ou doenças de um 
determinado tecido (OYAMA, 2015). O biomarcador ideal deve fornecer informações sobre diagnóstico, prognóstico ou resposta ao tratamento, apresentando dados precoces e mais sensíveis que os testes convencionais (OYAMA, 2015).

A avaliação das doenças cardiovasculares, em pequenos animais, normalmente é desafiadora para os médicos veterinários. O histórico e sinais clínicos de pacientes cardiopatas, na maioria das vezes, são inespecíficos, assim como as alterações detectadas na semiologia cardiovascular e a presença ou intensidade de um sopro cardíaco, que nem sempre se apresentam como uma avaliação confiável associada à gravidade da doença (OYAMA, 2015).

Doenças pulmonares, concomitantes à doença cardíaca descompensada podem promover dificuldades e desafios na interpretação das radiografias torácicas e, outros meios de diagnósticos, como a ecocardiografia, podem não ser prontamente acessíveis e indicados a pacientes cardiopatas em momento de estresse. Nesse contexto, o uso dos biomarcadores apresenta capacidade de detectar ou auxiliar no diagnóstico das doenças cardíacas (OYAMA, 2015; SMITH et al., 2015a). A capacidade dos biomarcadores em distinguir se a dispneia apresentada por um paciente é de causa cardíaca ou extra cardíaca, demonstra grande importância e interesse na rotina clínica e emergencial. $O$ diagnóstico precoce e viável em animais instáveis, proporciona melhor manejo e sucesso terapêutico (CONNOLLY et al., 2009).

Em detrimento dos avanços, biomarcadores como a porção $\mathrm{N}$-terminal do peptídeo natriurético tipo B e a troponina cardíaca I (cTnl), são os mais utilizados para doenças cardiovasculares (SMITH et al., 2015a; LANGHORN; WILLESEN, 2016). O primeiro é capaz de detectar o estresse de cardiomiócitos, em resposta à sobrecarga de volume ou de pressão, revelando congestão em nível celular, enquanto o segundo é um indicador bem estabelecido de lesão miocárdica, sendo presente quando há lesão e desintegração dos sarcômeros cardíacos (LANGHORN; WILLESEN, 2016).

Os biomarcadores específicos cardíacos apresentam potencial para identificar o desenvolvimento das disfunções cardíacas de forma mais precoce em comparação às avaliações clínicas convencionais, porém devem ser associados a exames complementares para melhor elucidação da doença (CHOW et al., 2017). O objetivo desta revisão de literatura foi descrever a utilidade dos biomarcadores cardíacos como auxiliares para o diagnóstico e prognóstico de cardiopatias em cães e gatos.

\section{BIOMARCADORES CARDÍACOS}

A doença valvar crônica degenerativa é a causa mais comum de insuficiência cardíaca congestiva no cão (ATKINS et al., 2009) e a cardiomiopatia hipertrófica é a doença cardíaca mais encontrada em gatos (BORGEAT et al., 2014). A monitorização da progressão dessas cardiopatias, quanto ao desenvolvimento de insuficiência cardíaca congestiva, depende normalmente de radiografias e ecocardiografias seriadas. $\mathrm{O}$ uso de exames ecocardiográficos, para estratificar o risco e monitorar a progressão da insuficiência cardíaca congestiva apresenta, em alguns momentos, acessibilidade limitada ao paciente. Assim, o uso em potencial dos biomarcadores cardíacos, para elucidar o diagnóstico e promover a monitoração, tanto da progressão, quanto da resposta à terapia em animais com doenças cardíacas, torna-se atraente para a conduta veterinária (REIMANN et al., 2016; WINTER et al., 2017). 
O potencial dos biomarcadores em identificar a doença cardíaca assintomática permite o diagnóstico precoce e mais sensível que os testes convencionais utilizados na rotina. Desse modo, possibilita estabelecer planos terapêuticos e de manejo, de forma segura e precoce, no intuito de preservar as funções sistêmicas, aumentar a expectativa de vida e melhorar a qualidade de vida dos pacientes (RUAUX et al., 2015; WINTER et al., 2017).

$\mathrm{O}$ interesse nos biomarcadores deve-se à necessidade de desenvolvimento de ensaios diagnósticos que possam ser realizados de forma simples, rápida e segura para a aplicação em animais que se encontram instáveis. Um exemplo pertinente são os casos de pacientes com desconforto respiratório, de origem cardiogênica, em que os testes podem auxiliar no diagnóstico e manejo da insuficiência cardíaca congestiva (ICC) aguda (SMITH et al., 2015a). Outra aplicação potencialmente explorada para esses métodos de diagnóstico na rotina clínica é o uso dos testes para estratificar o estágio da doença cardíaca em gatos com sopros cardíacos. Esses testes possuem capacidade de identificar animais com provável cardiomiopatia oculta e, portanto, com essa avaliação podem ser preditivos ao exame de ecocardiografia (BORGEAT et al., 2015).

Há grandes progressos nos estudos sobre os biomarcadores cardíacos, entretanto, não existe atualmente nenhum marcador cardíaco que tenha ganhado lugar no perfil bioquímico da rotina veterinária (ALVES et al., 2015; BOER et al., 2015; FERREIRA et al., 2016; MATTIN et al., 2018), embora os estudos já mostrem os benefícios da sua aplicação clínica na avaliação de pacientes graves, com ou sem doença cardíaca. Atualmente, a avaliação cardíaca na veterinária ainda se faz por meios de ausculta, radiografias, eletrocardiograma (ECG) e ecodopplercardiografia (ECO) (LANGHORN; WILLESEN, 2016; MILLER; JAFFE 2016).

\section{DEFINIÇÃO DOS BIOMARCADORES CARDÍACOS}

Os biomarcadores são substâncias específicas de um órgão ou tecido sob investigação, que são produzidos e secretados de acordo com um processo ou alteração local. São mensurados e avaliados por meio de amostras de fluidos corporais e são capazes de auxiliar na identificação de uma condição fisiológica ou normal, de processos patológicos ou anormais (BOER et al., 2015). Normalmente, podem ser aplicados como ferramenta para o estadiamento da doença ou classificação da extensão das lesões, como uma técnica auxiliar ao monitoramento e na previsão da resposta clínica terapêutica, além de atuar como indicador de prognóstico (KISHIMOTO et al., 2015; REIMANN et al., 2016; CHOW et al., 2017; WINTER et al., 2017).

Marcadores biológicos são considerados analitos circulantes da corrente sanguínea e são empregados clinicamente, com o objetivo de fornecer informações sobre o processo biológico em investigação, do qual outros meios convencionais são incapazes. Portanto, trata-se de um método prático para o uso na rotina clínica veterinária (KISHIMOTO et al., 2015).

O marcador cardíaco ideal precisa atender alguns critérios como: alta sensibilidade, devendo ser detectado precocemente, mesmo em baixa quantidade, em lesão miocárdica leve; alta especificidade, não sendo detectável em casos de lesões em outros órgãos ou tecidos; ser viável e de fácil acesso para a rotina clínica, facilmente adquirido e com baixo custo; apresentar boa janela para o diagnóstico, ou seja, identificar precocemente a alteração e apresentar retorno aos níveis basais de 
forma lenta, facilitando a identificação em outros momentos (OYAMA, 2015; BAISAN et al., 2016; CHOW et al., 2017).

\section{CLASSIFICAÇÃO DOS BIOMARCADORES CARDÍACOS}

Os marcadores cardíacos são classificados em: marcadores de estresse do miócito, que são compostos pelos peptídeos natriuréticos dos tipos $A$ e B; marcadores de lesão de miócito, representados pelas troponinas cardíacas dos tipos I e T, a creatinoquinase MB e o lactato desidrogenase. Existem também classes de marcadores neuro-humorais, constituídos pela endotelina e arginina vasopressina; e os marcadores da inflamação, como a proteína C reativa (CHOW et al., 2017). Entretanto, na medicina veterinária, estes dois últimos tipos não são específicos para doença miocárdica, não sendo, assim, apresentados nesta revisão.

\section{Peptídeos natriuréticos}

\section{BIOMARCADORES DE FUNÇÃO MIOCÁRDICA}

Os peptídeos natriuréticos são os principais marcadores de estresse do miócito na medicina veterinária. Na natureza, existem cinco tipos de peptídeos natriuréticos, são eles: o peptídeo natriurético tipo A (ANP); o peptídeos natriurético tipo B (BNP); o peptídeo natriuréticos tipo C (PNC); o peptídeo natriurético tipo dendroaspi (PND), encontrado no veneno da cobra Green Mamba; e o peptídeo natriurético tipo ventricular (PNV), sendo somente expresso em peixes (LIMA; FERREIRA, 2017). Os peptídeos natiuréticos do tipo A e B são produzidos principalmente por cardiomiócitos atriais e ventriculares e devido à falta de especificidade de outros peptídeos, além de alguns possuírem expressão somente em espécies específicas, os ANP e o BNP são os peptídeos natriuréticos mais estudados nas doenças cardiovasculares de cães e gatos (ANJOS et al., 2015; OYAMA, 2015; ALKHAWAN et al., 2016; KLÜSER et al., 2016).

$O$ peptídeo natriurético do tipo $A$, também conhecido como peptídeo natriurético atrial (ANP), e o peptídeo natriurético do tipo $B$ ou peptídeo natriurético cerebral (BNP), são os principais hormônios natriuréticos produzidos e secretados pelo músculo cardíaco, em resposta ao estresse ou estiramento dos cardiomiócitos, ocasionados pelas sobrecargas de volume, hipóxia e hipertrofia miocárdica (OYAMA, 2015; RUAUX et al., 2015; ALKHAWAN et al., 2016; PELANDER et al., 2017). Suas sínteses ocorrem a partir de precursores como longas sequências de peptídeos denominados proANP e proBNP e, após a transformação, são armazenados em grânulos ligados à membrana do tecido atrial e ventricular, respectivamente (DEL RY et al., 2014; CAHILL et al., 2015; HARRIS et al., 2017).

Os pro-hormônios, proANP e proBNP, são clivados em dois componentes quando secretados. Um como hormônio ativo na região C-terminal ou carboxiterminal, denominada C-ANP e C-BNP, que são secretados para a circulação, e seus respectivos fragmentos inativos $\mathrm{N}$-terminais ou amino-terminais, chamados de NT-proANP e NT-proBNP (OYAMA, 2015; SMITH et al., 2015b; CHOW et al., 2017; WINTER et al., 2017).

Os efeitos fisiológicos das frações ativas dos peptídeos natriuréticos induzem, via receptor do peptídeo natriurético do tipo $\mathrm{A}$, à diurese e à natriurese pelo aumento da taxa de filtração glomerular e inibição do transporte tubular de sódio pelo ducto coletor renal. Ambos medeiam a vasodilatação sistêmica e de arteríolas pulmonares, diminuindo a resistência vascular sistêmica e inibindo a liberação de renina e aldosterona. Esses receptores são encontrados nos pulmões, 
no coração, nos rins, nas adrenais, nos vasos e no sistema nervoso central. Um segundo receptor do tipo $B$ também responde à forma ativa de ANP e BNP. No entanto, a atuação desses sobre aquele receptor controla a regulação da vasodilatação local (CAHIL et al., 2015; HEZZEL et al., 2015; HARRIS et al., 2017) e provoca a inibição do sistema renina-angiotensina-aldosterona (SRAA) (OYAMA, 2015).

O peptídeo natriurético do tipo $B$, em condições normais, é encontrado em maiores quantidades nos átrios e em menor proporção pelos ventrículos. Porém, quando há alguma alteração de estresse ou estiramento do miocárdico como resultado da sobrecarga de volume, a sua principal fonte torna-se os ventrículos (DEL RY et al., 2014). O NT-proBNP e o BNP são importantes marcadores de hipertrofia ventricular e ICC (BORGEAT et al., 2014; KANNO et al., 2016; BORGES et al., 2018), e possuem valor, tanto no diagnóstico, como no prognóstico das cardiopatias (MATTIN et al., 2018).

O ANP é secretado principalmente por cardiomiócitos atriais, direito ou esquerdo. Entretanto, quando há estímulo de sobrecarga ventricular, isquemia e hipertrofia, há também liberação de ANP pelos cardiomiócitos ventriculares, em um nível equivalente aos liberados pelos cardiomiócitos atriais (DEL RY et al., 2014). A distensão da parede ou pressão atrial pelo aumento do volume plasmático e da pressão sanguínea arterial ou pulmonar, estimula a liberação e elevação significativa dos níveis de ANP. Em condições fisiológicas, a liberação de ANP é um mecanismo de proteção do organismo contra a sobrecarga de volume cardiovascular e na regulação da função renal (DEL RY et al., 2014; KANNO et al., 2016). Também atua na redução do débito cardíaco pela diminuição do volume vascular, e subsequente diminuição da pressão venosa central.

Após a sua ação, o ANP e BNP são retirados da circulação por dois mecanismos principais: pelo receptor de peptídeos natriuréticos tipo $\mathrm{C}$, que resulta na depuração por internalização dos peptídeos natriuréticos e posterior degradação lisossomal, ou através da enzima neutralizadora de endopeptídeos que quebra os peptídeos natriuréticos em fragmentos inativos. Os receptores apresentam maior afinidade pelo ANP, o que pode estar relacionado ao aumento do tempo de meiavida do BNP na circulação (HEZZEL et al., 2015; LIMA; FERREIRA, 2017).

Os ensaios relacionados aos fragmentos C-BNP e NT-proBNP foram usados para auxiliar na discriminação entre sinais clínicos de causa cardíaca e extracardíaca, e para estimar o risco de morbidade e mortalidade em pacientes com doença cardíaca crônica (FOX et al., 2015; SMITH et al., 2015b; HEISHIMA et al., 2018). As frações inativas $\mathrm{N}$-terminal possuem meia vida plasmática maior, em comparação às frações ativas dos peptídeos natriuréticos, desempenhando melhores resultados em suas mensurações (FOX et al., 2015; SOLTER et al., 2015; WINTER et al., 2017).

Existem três tipos de ensaios, que são comercialmente disponíveis para análise de peptídeos natriuréticos, sendo todos desenvolvidos para identificação das frações do BNP. Um deles detecta moléculas de BNP em cães (Cardio-BNPß, Antech Diagnostics, Chesterfield, MO) e outros dois detectam NT-proBNP em cães (CardioPet® proBNP-Canine, IDEXX Laboratories, Westbrook, ME) e em gatos (CardioPet ${ }^{\circledR}$ proBNP-Feline, IDEXX Laboratories, Westbrook, ME) (FOX et al., 2015; OYAMA et al., 2015; SOLTER et al., 2015; WINTER et al., 2017). 
Na medicina veterinária, a mensuração do NT-proBNP é recomendada, e têm sido validada, para auxiliar na identificação de doenças cardíacas ocultas, na diferenciação das dispneias de origem respiratória e de ICC (FOX et al., 2015; KANNO et al., 2016; LIMA; FERREIRA, 2017), na cardiomiopatia hipertrófica (CMH) em felinos (FREITAS et al., 2015; HEISHIMA et al., 2018), na cardiomiopatia dilatada (CMD) (WESS et al., 2017) e como valor prognóstico nas doenças degenerativas valvares (FOX et al., 2015; RUAUX et al., 2015; WINTER et al., 2017). No Quadro 1, apresentam-se os níveis séricos de NT-proBNP encontrados em cães e gatos, segundo recomendações do laboratório IDEXX (IDEXX LABORATORIES, 2013).

Estudos evidenciaram o aumento dos níveis séricos de peptídeos em animais com insuficiência cardíaca comparado às doenças respiratórias. Porém, tais achados somente podem ser validados com a análise conjunta dos biomarcadores, da avaliação clínica (histórico, anamnese e exame físico) e com auxílio de exames complementares (radiografias torácicas, ECG e ECO), sendo inválido o seu uso de forma singular, pois os exames complementares fornecem informações mais precisas sobre a estrutura e função cardíaca (OYAMA, 2015; CHOW et al., 2017).

QUADRO 1 - Valores do NT-proBNP para cães e gatos, segundo recomendações da IDEXX.

\begin{tabular}{|l|l|}
\hline \multicolumn{2}{|c|}{ Cães com suspeita de doença cardíaca (sopro ou raças de alto risco) } \\
\hline Normal (Não compatível com estresse e estiramento cardíaco) & $<900 \mathrm{pmol} / \mathrm{L}$ \\
\hline Elevado (Compatível com estresse e estiramento cardíaco) & $\geq 900 \mathrm{pmol} / \mathrm{L}$ \\
\hline \multicolumn{2}{|c|}{ Cães com sopro e sinais clínicos consistentes com doença cardíaca } \\
\hline Normal (Provável os sinais clínicos não serem de origem cardíaca) & $<900 \mathrm{pmol} / \mathrm{L}$ \\
\hline $\begin{array}{l}\text { Moderado (Provável doença cardíaca; necessita de mais exames para o } \\
\text { diagnóstico) }\end{array}$ & $900-1800 \mathrm{pmol} / \mathrm{L}$ \\
\hline Elevado (Alta probabilidade de ICC) & $>1800 \mathrm{pmol} / \mathrm{L}$ \\
\hline \multicolumn{2}{|c|}{ Gatos } \\
\hline Normal (Não compatível com estresse e estiramento cardíaco) & $<100 \mathrm{pmol} / \mathrm{L}$ \\
\hline Anormal (Compatível com estresse e estiramento cardíaco) & $\geq 100 \mathrm{pmol} / \mathrm{L}$ \\
\hline \multicolumn{2}{|c|}{ Gatos com sinais clínicos respiratórios } \\
\hline $\begin{array}{l}\text { Normal (Provável os sinais clínicos não serem de origem cardíaca, } \\
\text { necessita de mais exames para o diagnóstico) }\end{array}$ & $<270 \mathrm{pmol} / \mathrm{L}$ \\
\hline Elevado (Provável ICC) & $\geq 270 \mathrm{pmol} / \mathrm{L}$ \\
\hline
\end{tabular}

Adaptado de: IDEXX LABORATORIES, (2013).

Quando a avaliação clínica e os testes de diagnósticos tradicionais revelarem a causa dos sinais clínicos como as alterações respiratórias, o biomarcador não vai acrescentar valor adicional para o diagnóstico no paciente. No entanto, em casos que o diagnóstico ainda é incerto com os exames convencionais, o uso dos biomarcadores pode proporcionar melhores resultados e conclusões sobre os sinais clínicos observados (SINGLETARY et al., 2012; FOX et al., 2015; SMITH et al., 2015a; HEISHIMA et al., 2018).

Também foi observado que o BNP apresenta correlação com a severidade da lesão isquêmica, uma vez que essa aumenta o estresse da parede ventricular esquerda, promovendo o aumento da liberação de BNP na circulação, mesmo na ausência de necrose ou disfunção ventricular preexistentes (CELANO et al., 2017). Além do mais, esse peptídeo natriurético é útil no monitoramento de terapias com potencial cardiotoxicidade, como exemplo 0 uso da doxorrubicina, nas quimioterapias (GALLAY-LEPOUTRE et al., 2016). 
Estudos mostraram que as concentrações plasmáticas de ANP evidenciam aumentos em casos de insuficiência cardíaca descompensada. Porém foram observados que cardiopatas assintomáticos e animais clinicamente normais não apresentam diferenciação dos valores de ANP (HEISHIMA et al., 2018). Em cães, os níveis séricos de ANP aumentam com a elevação da pressão capilar pulmonar, o que revela aumento da pressão em câmara atrial esquerda (HORI et al., 2011). Valores acima de $25 \mathrm{pg} / \mathrm{mL}$ identificam cães com cardiopatias, e valores acima de $100 \mathrm{pg} / \mathrm{mL}$ identificam cães com insuficiência cardíaca descompensada (HORI et al., 2011).

Já foram observadas que as doenças secundárias que atingem o sistema cardiovascular também podem provocar elevação dos peptídeos natriuréticos, são exemplos o hipertireoidismo, a doença renal crônica e as hipertensões, tanto sistêmica quanto pulmonar (MENAUT et al., 2012; PELANDER et al., 2017; BORGES et al., 2018).

Como apresentado no Quadro 1, o NT-proBNP é capaz de diferenciar cães hígidos dos animais com doença cardíaca e também consegue identificar animais que possuem remodelamento cardíaco significativo (BOSWOOD et al., 2008; OYAMA, 2015). O uso associado de NT-proBNP com o NT-proANP, facilita o diagnóstico de causas cardíacas e extracardíacas em animais com distúrbios respiratórios (FOX et al., 2015; SMITH et al., 2015a). Portanto, todas essas avaliações propõem que o uso dos biomarcadores é útil na rotina da medicina veterinária. Alguns exemplos de valores e do uso dos biomarcadores são apresentados na Quadro 2.

QUADRO 2 - Uso de biomarcadores para o diagnóstico de doenças cardíacas em cães e gatos. Referências de valores relatados e o alcance das respectivas sensibilidades e especificidades para cada indicação apresentada.

\begin{tabular}{|c|c|c|c|c|c|}
\hline Indicação & Marcador & Valores & $\begin{array}{c}\text { Sensibilidad } \\
\text { e (\%) }\end{array}$ & $\begin{array}{c}\text { Especificidade } \\
(\%)\end{array}$ & Comentários \\
\hline $\begin{array}{l}\text { Sinais clínicos } \\
\text { respiratórios em } \\
\text { doença cardíaca vs } \\
\text { não cardíaca, } \\
\text { em gatos. }\end{array}$ & $\begin{array}{c}\text { NT- } \\
\text { proBNP }\end{array}$ & $\begin{array}{l}220 ; 265 \\
(\mathrm{pmol} / \mathrm{L})\end{array}$ & $90-94$ & 88 & $\begin{array}{c}\text { Valores baixos } \\
\text { indicam causas } \\
\text { extracardíacas e } \\
\text { altos sugerem ICC }\end{array}$ \\
\hline \multirow{2}{*}{$\begin{array}{l}\text { Sinais clínicos } \\
\text { respiratórios em } \\
\text { doença cardíaca vs } \\
\text { não cardíaca, } \\
\text { em cães. }\end{array}$} & $\begin{array}{c}\text { NT- } \\
\text { proBNP }\end{array}$ & $\begin{array}{c}1158 \\
1400 \\
\text { (pmol/L) }\end{array}$ & $86-92$ & 81 & \multirow{2}{*}{$\begin{array}{c}\text { Valores elevados } \\
\text { não são específicos } \\
\text { para doença } \\
\text { cardíaca primária }\end{array}$} \\
\hline & C-BNP & $\begin{array}{l}17,4 ; 6,0 \\
(\mathrm{pg} / \mathrm{mL})\end{array}$ & $86-90$ & 78-81 & \\
\hline $\begin{array}{c}\text { Detecção de } \\
\text { cardiomiopatia em } \\
\text { Gatos. }\end{array}$ & $\begin{array}{c}\text { NT- } \\
\text { proBNP }\end{array}$ & $\begin{array}{c}95 ; 99 \\
100 \\
\text { (pmol/L) }\end{array}$ & $71-92$ & $94-100$ & $\begin{array}{l}\text { Estudos foram } \\
\text { realizados em } \\
\text { populações com } \\
\text { suspeita de } \\
\text { cardiopatias }\end{array}$ \\
\hline \multirow[t]{2}{*}{$\begin{array}{c}\text { Detecção de } \\
\text { cardiomiopatia em } \\
\text { Doberman } \\
\text { pinschers. }\end{array}$} & $\begin{array}{c}\text { NT- } \\
\text { proBNP }\end{array}$ & $\begin{array}{l}457 ; 550 \\
(\mathrm{pmol} / \mathrm{L})\end{array}$ & $70-79$ & $81-90$ & $\begin{array}{l}\text { Necessita de } \\
\text { exames } \\
\text { complementares } \\
\text { para melhor } \\
\text { diagnostico. }\end{array}$ \\
\hline & C-BNP & $\begin{array}{c}6,2 \\
(p g / m L)\end{array}$ & 95 & 62 & $\begin{array}{l}\text { Grande número de } \\
\text { falsos positivos }\end{array}$ \\
\hline
\end{tabular}


Um estudo realizado com 77 cães determinou que as concentrações séricas e plasmáticas de NT-proBNP foram capazes de distinguir com precisão os pacientes com sinais clínicos de doença cardíaca das causas extracardíacas. A comparação dos resultados foi realizada com as concentrações do NT-proBNP, revelando variações nos valores mensurados nas diferentes amostras obtidas, entre soro e plasma, sendo a amostra de soro não fidedigna. Este estudo também apresentou a correlação entre os peptídeos natriuréticos com as concentrações de ureia e creatinina, sendo observados aumentos dos níveis de NT-proBNP em animais azotêmicos, justificado pela a redução da taxa de filtração glomerular e não em função do aumento da liberação dos peptídeos pelos cardiomiócitos. Portanto, a análise do NT-proBNP apresenta acurácia no diagnóstico de cardiopatias em cães com dispneia de origem cardiogênica, utilizando valor de corte de $210 \mathrm{pmol} / \mathrm{L}$ (BOSWOOD et al., 2008).

Connolly et al. (2008) desenvolveram pesquisa com felinos, que demonstrou que ambos os níveis séricos de NT-proANP e NT-proBNP podem ser utilizados para diferenciar animais com doença cardíaca de animais saudáveis, incluindo portadores de cardiomiopatias hipertrófica, obstrutiva, restritiva, dilatada, displasia mitral, arritmogênica do ventrículo direito e bloqueio átrio ventricular de terceiro grau. Neste estudo também foi observado que animais com ICC apresentavam concentrações séricas mais altas de ambos os peptídeos, em comparação com cardiopatas compensados. Como resultado, ambos os testes podem ser clinicamente úteis na rotina veterinária.

Outro estudo relatou que os níveis de NT-proBNP são altamente sensíveis e específicos em detectar $\mathrm{CMH}$ grave (espessura máxima da parede ventricular maior que $7 \mathrm{~mm}$ ) em felinos, mas não é sensível na detecção daqueles que apresentam $\mathrm{CMH}$ leve à moderada. Em decorrência a esses achados, concluíram-se que o teste não foi capaz de rastrear gatos com $\mathrm{CMH}$ leve a moderada (MACHEN et al., 2014).

Foi realizada a comparação dos níveis séricos de NT-proBNP, como triagem, em cães predispostos a cardiomiopatia dilatada, sendo avaliados 155 cães da raça Doberman, sendo 73 portadores de CMD oculta (CMDO) e 82 cães saudáveis. Todos os animais foram submetidos a exames ecodopplercardiográficos, Holter e mensuração de NT-proBNP. A mensuração de NT-proBNP, quando realizado em conjunto com Holter, apresentou-se altamente sensível $(94,5 \%)$ e específica $(87,8 \%)$ em detectar CMDO em Dobermans. Animais que apresentaram no Holter mais que 50 complexos ventriculares prematuros ou aumento da concentração de NT-proBNP, ou ambas alterações associadas, se enquadraram nos casos com probabilidade maior que sete vezes ou $87,3 \%$ de chance de apresentarem a CMDO. Em contrapartida, animais que não se encaixaram nesses critérios, a probabilidade de CMDO foi aproximadamente 16 vezes menor e com chance apenas de 5,3\%. Foram observados também que a sobrevivência média dos Dobermans com NTproBNP > 900pmol/L foi de 284 dias, mais curta que os Dobermans com NT-proBNP < 900pmol/L com 1743 dias. Os resultados mostraram que o teste NT-proBNP associado ao Holter foi preciso em detectar alto risco de desenvolver CMDO. Ainda, a mensuração do NT-proBNP foi importante para estimativa de sobrevida desses animais. Contudo, a mensuração de NT-proBNP não deve ser utilizada como critério único de diagnóstico de CMDO, pois seu uso não descarta os exames complementares, como a ecodopplercardiografia. Além disso, 
foi observado que uma concentração normal de NT-proBNP, avaliada em um único momento, não exclui a possibilidade de desenvolvimento futuro da CMD (SINGLETARY et al., 2012).

Em busca da relevância do diagnóstico com as mensurações de NT-proBNP e NT-proANP em cães com doença mixomatosa de valva mitral (DMVM), um estudo foi realizado, sendo o grupo controle com 116 cães sadios e outro grupo com 236 cães com DMVM (WOLF et al., 2013). Para o grupo controle, foram observados que a idade e o tamanho corporal não apresentaram influência nos resultados das mensurações dos peptídeos natriuréticos. No entanto, o sexo e animais não castrados, influenciaram significativamente nas concentrações de NT-proBNP e NTproANP. A mensuração dos peptídeos natriuréticos nas fêmeas íntegras foi maior que em comparação com cães machos inteiros. Enquanto que, a diferença de valores de fêmeas e machos castrados, não tiveram significância. Outro estudo sugeriu que a presença de substâncias andrógenas parece influenciar os níveis de BNP e NT-proBNP (CHANG et al., 2007). Considerando estes estudos, as diferenças nos intervalos de referência entre as mensurações de cães machos e fêmeas inteiras devem ser determinadas, de forma a auxiliar na interpretação dos resultados de NT-proBNP e NT-proANP.

No estudo de Wolf et al. (2013), o grupo com DMVM apresentou aumento nas concentrações dos peptídeos natriuréticos, tanto do NT-proBNP quanto do NTproANP, proporcionalmente em relação a gravidade da doença, mostrando ser útil na monitoração da progressão da doença. Ambos, foram capazes de discriminar pacientes com insuficiência cardíaca aguda em comparação a animais assintomáticos com DMVM, com um valor de corte de NT-proBNP de 1207pmol/L e de $1578 \mathrm{pmol} / \mathrm{mL}$ para o NT-proANP, apresentando boa sensibilidade $(83 \%$ e $83 \%$, respectivamente) e especificidade ( $85 \%$ e $86 \%$, respectivamente). Quando se usa o valor de corte de NT-proBNP maior que 1800pmol/L recomendado pelo fabricante, observam-se mudanças na especificidade (91\%) e sensibilidade (70\%), concluindose então que o NT-proBNP e o NT-proANP podem diferenciar cães com ICC de pacientes com MMVD sem ICC. Todavia, entretanto os testes não são úteis para detectar cães assintomáticos com DMVM, pela baixa sensibilidade e especificidade.

Outro estudo avaliou a variação nos valores de NT-proBNP em cães com diferentes estágios de DMVM. Foram admitidos 38 cães, incluindo 10 cães saudáveis como controle, 10 cães com DMVM estágio B1, 10 cães com DMVM estágio B2, e oito cães com DMVM estágio C. Foi utilizado o biomarcador NTproBNP (CardioPet $\AA$ proBNP-Canine, IDEXX Laboratories, Westbrook, ME) em tempos variados. Os resultados encontrados foram valores de NT-proBNP no grupo controle de 543pmol/L, enquanto no grupo DMVM os valores nos estágios B1, B2 e C, foram de $677 \mathrm{pmol} / \mathrm{L}, 1.553 \mathrm{pmol} / \mathrm{L}$ e $1,963 \mathrm{pmol} /$, respectivamente. Por fim, observou-se que cães com maiores níveis séricos de NT-proBNP sobrevivem menor tempo em relação àqueles com valores mais baixos de NT-proBNP (WINTER et al., 2017).

Investigando a relação entre NT-proBNP e a persistência do ducto arterioso (PDA) em cães, comparando com animais saudáveis, pode-se observar que os valores do NT-proBNP são elevados nesses pacientes. A mensuração do peptídeo natriurético teve correlação positiva com aumento de Vertebral Heart Size (VHS) e remodelamento das câmaras cardíacas. Os animais com PDA foram submetidos a mensuração dos níveis de NT-proBNP antes e após o procedimento cirúrgico para a 
oclusão do ducto. Os níveis séricos de NT-proBNP, antes da cirurgia foram significativamente maiores $895 \mathrm{pmol} / \mathrm{L}$, comparados com o grupo controle 663pmol/L. Após 90 dias da oclusão, os níveis de NT-proBNP caíram consideravelmente para $597 \mathrm{pmol} / \mathrm{L}$, observando-se também diminuição do átrio esquerdo, por outros métodos. Os autores concluíram que o uso de NT-proBNP como método de acompanhamento em cães com PDA é uma importante ferramenta para avaliar os resultados pós-operatórios. Além disso, a redução dos níveis de NT-proBNP, após o procedimento cirúrgico, foi um bom marcador na avaliação prognóstica e hemodinâmica desses pacientes (HARIU et al., 2013).

Um estudo retrospectivo, realizado para investigar as aplicações clínicas dos níveis plasmáticos de NT-proBNP em cães com estenose pulmonar (EP), mostrou que a concentração plasmática de NT-proBNP em cães com EP sintomática foi significativamente maior que nos animais do grupo controles e aqueles com EP assintomáticos. O valor de corte utilizado de NT-proBNP maior que $764 \mathrm{pmol} / \mathrm{L}$, sugere EP grave, e apresentou sensibilidade de $76,2 \%$ e especificidade de $81,8 \%$. Estes resultados indicaram que o NT-proBNP é um método útil para avaliação do estado hemodinâmico de paciente com EP (KOBAYASHI et al., 2014).

\section{Troponinas cardíacas}

\section{BIOMARCADORES DE LESÃO MIOCÁRDICA}

As troponinas possuem estruturas moleculares muito parecidas entre as espécies, e vêm sendo preferíveis na avaliação de lesão cardíaca em mamíferos como marcador altamente específico (OYAMA, 2015; LANGHORN; WILLESEN, 2016). Essas substâncias formam um complexo proteico, denominado troponinatropomiosina, encontrados no interior dos sarcômeros dos músculos estriados, e responsáveis por regular a ligação de cálcio e subsequente interação entre os filamentos de actina e miosina. Esse complexo é formado por uma molécula de tropomiosina e por três moléculas de troponinas, troponina C (TnC), I (Tnl) e T (TnT), e possuem ação na regulação da contração muscular (LANGHORN; WILLESEN, 2016).

A Tnl é a subunidade inibitória, que se liga à actina promovendo uma ação, em conjunto com a tropomiosina, de criar um obstáculo espacial e inibir a interação da actina com a miosina. A TnC é a subunidade que se liga ao cálcio e a TnT é a subunidade estrutural, que liga o complexo troponina à tropomiosina, formando o complexo troponina-tropomiosina. Com a despolarização do sarcolema, há a liberação de cálcio para o citoplasma, e a TnC se liga ao cálcio e remove os efeitos inibitórios da Tnl. Assim, a tropomiosina consegue se deslocar, devido à remoção do obstáculo espacial da interação de actina-miosina e liberação da inibição da actinamiosina-ATPase, permitindo a hidrólise do ATP e a contração muscular. Após isto o cálcio é novamente bombeado para o interior do retículo sarcoplasmático e 0 complexo volta para a conformação original, inibindo a ação da actina com a miosina e ATPase, promovendo o relaxamento muscular (LANGHORN et al., 2014; LANGHORN; WILLESEN, 2016).

Quando ocorre lesão dos cardiomiócitos e das membranas sarcolemais, o complexo troponina dissocia-se dos filamentos da actina, o que propicia 0 extravasamento das troponinas para o espaço extracelular, alcançando a circulação sanguínea. Portanto, após a lesão em cardiomiócitos têm-se o aumento dessas substâncias na corrente sanguínea, e sua mensuração pode identificar previamente 
que há lesão em cardiomiócitos. Com base nesses achados, foi possível identificar a troponina como um biomarcador cardíaco (OYAMA, 2015).

A troponina I cardíaca (cTnl) é específica do tecido cardíaco, a liberação na circulação está relacionada às áreas de lesão e necrose irreversível de cardiomiócitos, já que a isquemia causa degradação proteolítica intracelular, levando ao aumento de cTnl (DANIELS; MAISEL, 2015; RUAUX et al., 2015). Em pacientes saudáveis esta troponina cardíaca apresenta concentração ínfima ou mesmo ausente, e a concentração sanguínea costuma ser proporcional à severidade da lesão (MATTIN et al., 2018). Já a troponina T cardíaca (cTnT) não é totalmente cardio-específica, é expressa no músculo em regeneração, mesmo sendo apenas o músculo esquelético normal. A elevação da concentração de cTnT sanguínea pode ocorrer na ausência de envolvimento miocárdico, em pacientes com polimiosite, rabdomiólise, doença muscular crônica e insuficiência renal (POLIZOPOULOU et al., 2014; CHOW et al., 2017).

As troponinas são proteínas com localização intracelular que, quando encontradas na circulação, indicam que houve liberação de conteúdo celular de cardiomiócitos. Após um insulto cardíaco, observa-se que as concentrações de troponina I cardíaca são mais altas que a cTnT (OYAMA, 2015; LANGHORN et al., 2014; CHOW et al., 2017). Acredita-se que este fato está relacionado ao menor tamanho molecular da cTnl, podendo passar facilmente pela membrana, no qual resulta em um aumento inicial da troponina circulante. Também, tem sido sugerido que a cTnT apresenta-se fortemente ligada ao aparato contrátil, em relação a cTnl, sendo liberada de forma lenta à medida que é lesionado, assim há um aumento da cTnT de forma sustentada por dias e até semanas (LANGHORN et al., 2016). Em conclusão, pode-se observar que as concentrações aumentadas de cTnT e cTnl refletem uma lesão cardíaca mais grave, em relação a um aumento isolado de cTnl. Em cães, a fração de troponina livre no citosol corresponde de 2 a $8 \%$ da cTnl e 6 a 8\% da cTnT, do total presente no cardiomiócito (BOER et al., 2015).

O tempo estimado até as concentrações e elevações máximas das troponinas vai depender da causa e do mecanismo de liberação das mesmas, no entanto, após lesão cardíaca estipula-se um aumento de troponinas dentro de duas a três horas, sendo o pico alcançado em 18 a 24 horas, o que sugere que níveis elevados persistentes de troponinas, indicam lesão miocárdica contínua, e após liberadas, sofrem proteólise, oxidação e redução da circulação, como resultado transformam em uma variedade de peptídeos circulantes (KATUS et al, 1991).

Alguns mecanismos ainda não foram elucidados, mas especula-se que o aumento de cTnl livre no citosol, pós exercício intenso, ocorre devido ao aumento da permeabilidade da membrana celular do miocárdico e não devido à lesão necrótica permanente e morte celular, semelhante ao que ocorre por exemplo, quando equinos realizam teste de exercício intenso, ocasionam hipoxemia que propicia maior estresse cardiovascular, levando ao aumento da cTnl (LEE et al., 2016; SHIELDS et al., 2016).

As troponinas cardíacas vêm se tornando alvo de pesquisas na medicina veterinária nos últimos anos. O aumento de seus níveis na circulação, já foi descrito em cães com CMD (GALLAY-LEPOUTRE et al., 2016), degeneração da valva mitral (RUAUX et al., 2015; WINTER et al., 2017), ICC (MATTIN et al., 2018), além de outras enfermidades que causam lesão cardíaca secundária, como a dilatação vólvulo gástrica (SHARP; ROZANSKI, 2014) e babesiose (KÖSTER et al., 2015). Já 
em gatos, níveis elevados de cTnl circulantes foram descritos em casos de $\mathrm{CMH}$ (LANGHORN et al., 2014). Um estudo apontou que em felinos com $\mathrm{CMH}$, níveis circulantes de cTnl maiores que $0,7 \mathrm{ng} / \mathrm{mL}$, foram importantes preditores de falência cardíaca. Tais dados foram relatados independente da presença de insuficiência cardíaca ou dilatação atrial esquerda (BORGEAT et al., 2014). Em cães da raça Greyhound, foram encontrados níveis séricos maiores de cTnl comparados a outras raças (COUTO et al., 2015).

Atualmente existem dois ensaios comerciais que estão disponíveis para a avaliação de troponinas cardíaca, o i-Stat®) (Cardiac Troponin assay, Abaxis, Union City, CA) e o Troponin-I® (IDEXX Laboratories, Westbrook, ME), ambos desenvolvidos para mensurar níveis de cTnl. Porém, esses testes não demonstraram alta sensibilidade como os utilizados para humanos (OYAMA, 2015).

Os índices elevados de troponina cardíaca mostram-se sensíveis à presença de lesão miocárdica, porém ainda não são específicos para causas cardíacas. Animais com doença cardíaca leve podem apresentar níveis de concentrações normais de cTnl. Em animais com doença cardíaca e doença renal, seja crônica ou aguda, pode-se observar elevados níveis de troponinas séricas, devido à falha na excreção renal, não justificando a gravidade da doença (PARIKH et al., 2015; PELANDER et al., 2017).

As troponinas cardíacas circulantes apresentam características ideais para um biomarcador, pois apresentam especificidade cardíaca, alta sensibilidade a lesões, precocidade no diagnóstico de lesões cardíacas (LANGHORN; WILLESEN, 2016) e mínima presença na circulação de indivíduos saudáveis. Elas conseguem persistir na circulação por dias e possuem boa correlação com a gravidade da lesão. No entanto, é importante relembrar que estas não são específicas da doença, pois um aumento na concentração de troponina reflete a lesão miocárdica, independentemente de qual a causa. Os valores considerados normais para felinos e caninos de troponinas são $0,02 \mathrm{ng} / \mathrm{dL}$ e $0,04 \mathrm{ng} / \mathrm{dL}$, respectivamente (WINTER et al., 2017).

Alguns estudos apontaram que a concentração da cTnl aumentou significativamente com a idade do animal (OYAMA; SISSON, 2004). Essa correlação sugere que alterações cardíacas com o extravasamento de cTnl, podem ser influenciados pela idade avançada. A lesão nos cardiomiócitos favorecida pela idade pode ocorrer por causa dos defeitos no potencial de oxigenação no miocárdio (RUAUX et al., 2015; WINTER et al., 2017).

O uso da troponina em animais com sinais respiratórios de causas não cardíacas é limitado. Qualquer condição sistêmica que provoca hipoxemia e isquemia de cardiomiócitos pode resultar na elevação da concentração de cTnl no sangue, não sendo específico de doença cardíaca primária. Portanto, este teste não é útil na diferenciação de sinais respiratórios de causas cardíacas e extracardíacas em cães e gatos (SMITH et al., 2015a). Observa-se no Quadro 3, as principais afecções cardíacas e extracardíacas que levam ao aumento da cTnl no sangue (PROSEK; ETTINGER, 2010). 
QUADRO 3 - Doenças de causas cardíacas e extracardíacas que promovem o aumento da cTnl na circulação sanguínea de cães e gatos.

\begin{tabular}{|l|l|}
\hline Causas cardíacas & Causas extracardíacas \\
\hline $\begin{array}{l}\text { Cardiomiopatia arritmogênica do ventrículo } \\
\text { direito em Boxers }\end{array}$ & Trauma torácico \\
\hline Infarto do miocárdio & Tromboembolismo \\
\hline Cardiotoxicidade induzida por doxorrubicina & Dilatação vólvulo-gástrica \\
\hline Miocardite & Piometra \\
\hline Insuficiência cardíaca congestiva & Sepse \\
\hline Estenose subaórtica & Doença pulmonar \\
\hline Cardiomiopatia dilatada e hipertrófica & Hipóxia \\
\hline Endocardiose & Hemoparasitose (Babesiose, erliquiose) \\
\hline Efusão pericárdica & Injúria renal \\
\hline & Neoplasia (Linfoma) \\
\hline & Epilepsia \\
\hline
\end{tabular}

Adaptado de: Prosek e Ettinger (2010).

O uso das troponinas não substitui o uso de métodos de diagnósticos complementares como as radiografias, ECO e ECG, sendo apenas uma ferramenta auxiliar para o diagnóstico das cardiopatias (OYAMA, 2015). Um estudo realizado com 53 felinos, sendo 30 gatos apresentando dispneia de origem respiratória e 23 gatos apresentando dispneia de origem cardíaca, observou-se que 14 dos 30 gatos com dispneia não cardiogênica (46,6\%) e 20 dos 23 gatos com dispneia cardiogênica por ICC (87\%), apresentaram dosagem sérica de cTnl entre 0,2 e $0,42 \mathrm{ng} / \mathrm{mL}$, reduzindo assim a utilidade clínica do ensaio, devido a significativa quantidade de sobreposição entre os valores dosados nos dois grupos. Também foi avaliado que níveis de cTnl com concentrações de $0,81 \mathrm{ng} / \mathrm{ml}$ pode discriminar com precisão as dispneias de origem não cardiogênica das dispneias de origem cardiogênica (ICC) em gatos, apresentando sensibilidade e especificidade de $65,2 \%$ e 90,0\% respectivamente. Concluiu-se que esse ensaio não deve ser utilizado como um método singular de diagnóstico, e sim ser associado a outros métodos de diagnósticos (CONNOLLY et al., 2009).

Outro estudo mais recente, utilizou 181 gatos, sendo 88 gatos clinicamente saudáveis e $93 \mathrm{com} \mathrm{CMH}$ e cardiomiopatia hipertrófica obstrutiva (CMHO). Foi possível concluir que a média da concentração de cTnl foi de $0,027 \mathrm{ng} / \mathrm{mL}$ em gatos sadios e que a concentração de $\mathrm{cTnl}$ de $0,163 \mathrm{ng} / \mathrm{mL}$ exclui gatos com $\mathrm{CMH}$ e CMHO, com sensibilidade $62,0 \%$ e especificidade de $100 \%$. Foi determinado também, que a concentração plasmática de $\pm 0,234 \mathrm{ng} / \mathrm{mL}$ reflete a gravidade da doença de gatos com $\mathrm{CMH}$ e $\mathrm{CMHO}$, quando outras causas de lesões cardíacas forem descartadas. Para distinguir gatos sem/com dilatação atrial esquerda, foi observado um ponto de corte de $0,213 \mathrm{ng} / \mathrm{mL}$, com sensibilidade de $84,6 \%$ e especificidade de $84,9 \%$ (HORI et al., 2018).

Neste estudo foi possível diferenciar gatos sem/com IC, com um ponto de corte de $0,234 \mathrm{ng} / \mathrm{mL}$ e sensibilidade de $95,0 \%$ e especificidade de $77,8 \%$. Contudo, uma alta concentração plasmática de cTnl (> 0,7ng/ml) apresentou grande relevância clínica, sendo um fator importante de mau prognóstico em gatos com $\mathrm{CMH}$, independentemente se já tinham um quadro de IC ou dilatação atrial esquerda. Portanto, este trabalho mostrou que os níveis de cTnl foram significativamente maiores em gatos doentes em comparação com os gatos 
saudáveis, assim como as concentrações foram maiores em gatos com IC dos animais assintomáticos (HORI et al., 2018).

Um estudo sobre o valor diagnóstico das troponinas I, foi conduzido em cães portadores de doença mixomatosa valvar mitral, e evidenciou concentrações plasmáticas elevadas de cTnl nos cães com doença moderada $0,054 \mathrm{ng} / \mathrm{mL}$ e severa $0,092 \mathrm{ng} / \mathrm{mL}$ quando comparadas com o grupo de cães saudáveis $0,001 \mathrm{ng} / \mathrm{mL}$. Os resultados revelaram que a concentração plasmática de cTnl aumentou de acordo com a gravidade da doença mixomatosa valvar mitral, indicando danos aos cardiomiócitos, subsequentes a um processo de remodelamento cardíaco crônico (WINTER et al., 2017).

Nos cães portadores de cardiomiopatia dilatada, foi realizado um estudo com o total de 447 mensurações de cTnl, sendo 264 mensurações em Dobermans saudáveis e 206 medidas de cTnl em 75 Dobermans com cardiomiopatia dilatada. Os resultados observados foram que o grupo incluindo animais em risco de desenvolver a doença, os citados como incipientes, e o grupo de animais que possuíam 4100 complexos ventriculares prematuros em Holter de 24 horas, tiveram valores significativamente mais altos que o grupo controle. Um valor de corte de 0,22ng/mL apresentou uma sensibilidade de 79,5\% e uma especificidade de $84,4 \%$ em detectar todas as formas da cardiomiopatia. Como conclusão, foi mencionado que a mensuração de cTnl, apresenta importância clínica por ser um teste capaz de detectar cardiomiopatia em animais normais (WESS et al., 2010).

Em um total de 269 cães foram realizadas análises da concentração plasmática de cTnl, sendo 176 saudáveis, 26 portadores de cardiomiopatia dilatada (CMD), 37 portadores de doença valvar mitral (DVM) e 30 cães com estenose da válvula aórtica (EAo). A concentração plasmática de cTnl foi de $0,03 \mathrm{ng} / \mathrm{mL}$ no grupo de cães saudáveis, $0,14 \mathrm{ng} / \mathrm{mL}$ em cães portadores de CMD, $0,11 \mathrm{ng} / \mathrm{mL}$ nos cães com DVM e $0,08 \mathrm{ng} / \mathrm{mL}$ em cães com EAo. A concentração plasmática foi correlacionada com o remodelamento ventricular e atrial esquerdo em cães com CMD e DVM. Portanto, os níveis de cTnl no plasma encontram-se elevados em cães com doença cardíaca, correlacionado ao remodelamento cardíaco e com a sobrevivência (OYAMA; SISSON, 2004).

Além de pesquisas voltadas para avaliação das troponinas em animais portadores de doenças cardíacas, outros estudos foram desenvolvidos com o uso da troponina em animais infectados por hemoparasitoses, como a babesiose. Utilizando 50 cães infectados por Babesia canis e 20 animais saudáveis como grupo controle, foi realizada avaliação dos níveis de troponinas nesses animais. Neste estudo, 38\% dos cães com babesiose, tiveram o nível de troponina I no soro, com valores acima do normal (maior que $0,2 \mathrm{ng} / \mathrm{mL}$ ). Em dois cães, que vieram a óbito pela babesiose, foi observado que o nível de troponina estava muito alto com valores de $14 \mathrm{e}$ $26,7 \mathrm{ng} / \mathrm{dL}$, respectivamente. Como resultados foram observados que as alterações cardíacas são comuns em cães infectados com babesiose. O uso da cTnl é inespecífico, mas altas concentrações podem ser úteis como avaliação de prognóstico (BARTNICKI et al., 2017).

\section{Creatinoquinase}

A creatinoquinase $(C K)$ é uma molécula que possui a função de tornar adenosina trifosfato (ATP) disponível para a contração muscular, por meio da fosforilação de adenosina difosfato (ADP) e creatina fosfato. São três as isoenzimas 
formadas: CK-BB (CK1), predominante no cérebro e sistema digestório; CK-MB (CK2), presente no tecido cardíaco, nos rins, nos intestinos e nos pulmões; e CKMM (CK3), presente no músculo estriado. A determinação da CK pode ser realizada no soro ou plasma heparinizado, e a hemólise e a hiperbilirrubinemia podem resultar em falsos aumentos (AKTAS et al., 1993). Pode-se mensurar, tanto por sua atividade sérica por meio de testes bioquímicos, como pela concentração total (CK massa), utilizando ensaios imunométricos. As isoenzimas podem ser separadas por eletroforese, técnicas imunológicas e cromatografia de troca iônica. Os métodos imunológicos requerem anticorpos monoclonais espécie-específicos (CARDINET, 1997).

O aumento da atividade sérica da CK-MB já foi relatado em cães com comprometimento miocárdico secundário à parvovirose, dirofilariose e endocardite (AKTAS et al., 1993; CENK; MAHMUT, 2015). Níveis de CK-MB são significativamente maiores em cães com algum tipo de doença cardiovascular quando comparados a cães hígidos e também quando há alterações de hipóxia, que provocam instabilidade e altera a permeabilidade da membrana dos miócitos (PINO et al., 2008).

A CK-MB não é considerada um marcador cardíaco adequado em cães, por ser pouco específico para a espécie, principalmente em casos de acometimento associado a lesão muscular esquelética, pela baixa sensibilidade nas primeiras horas de evolução, devido à demora em ser liberada na corrente sanguínea e a detecção em lesões miocárdicas leve, além de representar índices de 4 a 13\% da atividade total da CK no miocárdio (AKTAS et al., 1993). Assim, houve a necessidade da busca por outros métodos ou novos marcadores para o diagnóstico de lesão celular miocárdica, visando a superar as limitações (GARG et al. 2017).

Um estudo realizado por Bartinicki et al. (2017), a fim de verificar as desordens cardíacas em decorrência da infecção por babesiose em cães, que podem levar a morte de animais infectados, investigou que os níveis de CK-MB em cães infectados por Babesia canis foram altos, variando de $23,17 \mathrm{U} / \mathrm{L}$ a $369,62 \mathrm{U} / \mathrm{L}$, obtidos de 50 soros de animais doentes, em que 49 amostras tinham os níveis altos. As maiores concentrações foram relatadas em cães que morreram devido à doença $(367,33 \mathrm{U} / \mathrm{L}$ e $369,62 \mathrm{U} / \mathrm{L})$. Concluiu-se que altas concentrações de CK-MB podem ser utilizadas como indicadores de prognóstico nesses animais.

\section{Lactato desidrogenase}

A lactato desidrogenase é a enzima responsável pela oxidação e redução do lactato para piruvato no ciclo final da glicólise. Duas subunidades, M (músculo) e/ou H (coração), podem estar presentes em uma molécula de LDH (SCHOBER, 2010). Trata-se de um marcador de necrose celular, que foi encontrado em altas quantidades em pacientes com isquemia e lesões teciduais no miocárdio (MILNE; DOXEY, 1987). Casos de hiperlactatemia estão associados à diminuição da perfusão tecidual, em resultado a situações de choque (hipovolêmico, cardiogênico e séptico) (STEVENSON et al., 2007). A falta de especificidade da LDH para lesão miocárdica, não configura este marcador como um método recomentado para auxiliar no diagnóstico para doenças cardíacas em cães e gatos. Já foram observadas sinalizações de LDH encontradas no músculo esquelético, eritrócitos, cérebro, rins, pâncreas, estômago (SCHOBER, 2010), células hepáticas e pulmonares (STEVENSON et al., 2007). 


\section{CONSIDERAÇÕES FINAIS}

Os biomarcadores estão sendo estudados e cada vez mais utilizados na rotina clínica da medicina veterinária. Há uma busca constante por biomarcadores que sejam específicos e sensíveis para avaliação dos pacientes, e que auxiliem no diagnóstico clínico de forma precoce e confiável.

Os marcadores cardíacos já são amplamente utilizados na rotina clínica médica e na medicina veterinária em diversos países, porém este cenário muda na rotina da medicina veterinária do Brasil, em que ainda são restritos apenas à pesquisa. Não obstante ao crescente número de estudos sobre os biomarcadores e a padronização dos testes e valores, ainda há limitações da aplicabilidade dos testes na rotina clínica. O custo elevado, a indisponibilidade e a confiabilidade dos biomarcadores propicia restrição em seu uso na prática.

O diagnóstico de doença cardiovasculares em cães e gatos representam um desafio para os médicos veterinários principalmente quando são observadas doenças pulmonares concomitantes. Distinguir as causas cardíacas e extracardíacas do desconforto respiratório em animais que podem se apresentar instáveis, intolerantes ao manejo clínico e a intervenção diagnóstica, podem ocasionar maior estresse e até levar o animal a óbito. Nestes casos, os testes com biomarcadores são úteis quando uma pequena amostra de sangue pode ser obtida com restrição mínima, sendo mais seguro e fácil em detectar a causa principal das alterações.

Com base nessa revisão, observa-se que o NT-proBNP é o biomarcador mais indicado para auxílio no diagnóstico de doenças cardíacas primárias, principalmente em casos de ICC, no qual, a sobrecarga das câmaras cardíacas, estimulam sua liberação na corrente sanguínea. Já a mensuração de cTnl é um método auxiliar de diagnósticos das doenças que provocam danos em cardiomiócitos, promovendo o extravasamento e liberação de cTnl na corrente sanguínea, como nos casos de miocardites ou lesão miocárdica cardíaca. Os estudos com esses biomarcadores mostraram que ambos são funcionais em monitorar as doenças cardíacas, sendo um bom indicador de gravidade e sobrevida.

Estudos com o CK-MB e o LDH, confirmaram tratar de marcadores de lesão miocárdica menos específicos que a cTnl. Ambos não configuram como um método recomentado para auxiliar no diagnóstico de doenças cardíacas em cães e gatos. As troponinas são consideradas como os marcadores preferíveis de lesão cardíaca em mamíferos.

Embora a ecocardiografia, a eletrocardiografia e as radiografias torácicas sejam exames de eleição para o diagnóstico das cardiopatias, esses exames podem não ser prontamente disponíveis e acessíveis no momento de descompensação do paciente. Em casos de pacientes instáveis, devido ao manuseio e estresse provocados na tentativa de conseguir realizar o exame, os mesmos não são indicados naquele momento, pois podem piorar o quadro clínico do animal. Mas os exames complementares não podem ser descartados após a estabilização do paciente.

Os biomarcadores sanguíneos disponíveis no mercado são capazes de detectar ou auxiliar no diagnóstico das doenças cardíacas e fornecer informações precisas para distinguir dispneias de causas cardíacas das causas extracardíacas. $O$ seu uso, não como um exame singular, mas de forma auxiliar na investigação 
diagnóstica de doenças cardíacas, promove um diagnóstico precoce e cria oportunidades de estabelecer melhores manejos terapêuticos.

\section{REFERÊNCIAS}

AKTAS, M.; AUGUStE, D.; LEFEBVRE, H. P.; TOUTAIN, P. L.; BRAUN, J. P. Creatine kinase in the dog: a review. Veterinary research communications, v. 17, n. $5, \quad$ p. 353-369, $1993 . \quad$ Disponivel em: https://www.ncbi.nlm.nih.gov/pubmed/8209415.

ALKHAWAM, H.; EL-HUNJUL, M.; NGUYEN, J.; DESAI, R.; SYED, U.; VITTORIO, T. J. Natriuretic peptide hormones in congestive heart failure: challenges, clinical interpretation and review of studies. Acta Cardiologica, v. 71, n. 4, p. 417-24, Aug 2016. DOI: 10.2143/AC.71.4.3159694. Disponivel em: https://www.ncbi.nlm.nih.gov/pubmed/27594357.

ALVES, A. C.; SOUSA, V. R. F.; SILVA, E. P.; NÉSPOLI, P. E. B. SILVA, F. G.; ALMEIDA, A. B. P. F. Biomarkers CK-NAC, CK-MB and troponin I in dogs with heart disease. Archives of Veterinary Science, v. 20, n. 2, p. 103-108, 2015. Disponivel em: https://www.researchgate.net/publication/296906374_Biomarkers_CK-NAC_CKMB_and_troponin_I_in_dogs_with_heart_disease.

ANJOS, D. S.; CINTRA, C. A.; ROCHA, J. R.; JUNIOR, D. P. Cardiac biomarkers an ally in the prognosis of heart disorders in small animals. Revista Investigação Medicina Veterinária, v. 14, n. 6, p 38-45, 2015.

ATKINS, C.; BONAGURA, J.; ETTINGER, S.; FOX, P.; GORDON, S.; et al. Guidelines for the diagnosis and treatment of canine chronic valvular heart disease. Journal of veterinary internal medicine, v. 23, n. 6, p. 1142-1150, 2009. Disponível em: <https://doi.org/10.1111/j.1939-1676.2009.0392.x>.

BAISAN, R. A.; ROSA, A.; DI LORIA, A.; VULPI, V.; PIANTEDOSI, D. Cardiac biomarkers in clinical practice of $\mathrm{dog}$ and cat-a review. Human and Veterinary Medicine, v. 8, n. 1, p. 50-58, 2016. Disponível em: http://www.hvm.bioflux.com.ro/docs/2016.50-58.pdf.

BARTNICKI, M.; LYP, P.; DEBIAK, P.; STANIEC, M.; WINIARCZYKET, S.; et al. Cardiac disorders in dogs infected with Babesia canis. Polish journal of veterinary sciences, v. 20, n. 3, p. 573-581, 2017. DOI 10.1515/pjvs-2017-0070. Disponivel em: https://content.sciendo.com/downloadpdf/journals/pjvs/20/3/article-p573.xml.

BOER, R. A.; DANIELS, L. B.; MAISEL, A. S.; JANUZZI JR, J. L. State of the Art: Newer biomarkers in heart failure. European Journal of Heart Failure, v. 17, n. 6, p. 559 - 569, Jun/2015. Disponível em: https://doi.org/10.1002/ejhf.273.

BORGEAT, K.; CONNOLLY, D. J.; LUIS FUENTES, V. Cardiac biomarkers in cats. Journal of Veterinary Cardiology, v. 17 Suppl 1, p. S74-86, Dec/2015. ISSN 17602734. Disponível em: < http://dx.doi.org/10.1016/j.jvc.2015.08.001 >. 
BORGEAT, K. SHERWOOD, K.; PAYNE, J. R.; LUIS FUENTES, V.; CONNOLLY, D. $\mathrm{J}$. Plasma cardiac troponin I concentration and cardiac death in cats with hypertrophic cardiomyopathy. Journal of veterinary internal medicine, v. 28, n. 6 , p. 1731-1737, 2014. Disponível em: <https://doi.org/10.1111/jvim.12459>.

BORGES, V. T. M.; ZANATI, S. G.; PARAÇOLI, M. T. S.; POIATI, J. R.; ROMÃOVEIGA, M.; et al. Maternal left ventricular hypertrophy and diastolic dysfunction and

brain natriuretic peptide concentration in early-and late-onset

pre-eclampsia. Ultrasound in Obstetrics \& Gynecology, v. 51, n. 4, p. 519-523,

2018. Doi: 10.1002/uog.17495. Disponível em:

https://www.ncbi.nlm.nih.gov/pubmed/28436119.

BOSWOOD, A.; DUKES-MCEWAN, J.; LOUREIRO, J.; JAMES, R. A.; MARTIN, M.; et al. The diagnostic accuracy of different natriuretic peptides in the investigation of canine cardiac disease. Journal of small animal practice, v. 49 , n. 1, p. 26-32, 2008. DOI: 10.1111/j.1748-5827.2007.00510.x. Disponível em: https://www.ncbi.nlm.nih.gov/pubmed/18005104.

CAHILL, R. J.; PIGEON, K.; STRONG-TOWNSEND, M. I.; DREXEL, J. P.; CLARK, G. H.; et al. Analytical validation of a second-generation immunoassay for the quantification of N-terminal pro-B-type natriuretic peptide in canine blood. Journal of Veterinary Diagnostic Investigation, v. 27, n. 1, p. 61-67, 2015. DOI: $10.1177 / 1040638714562826$.

em: https://www.ncbi.nlm.nih.gov/pubmed/25525139.

CARDINET, G. Skeletal muscle function. In: KANEKO, J. J.; HARVEY, J. W.; BRUSS, M. L. (Ed.). Clinical Biochemistry of Domestic Animals. San Diego: Academic, p.407-440. 1997.

CELANO, C. M.; BEALE, E. E.; BEACH, S. R.; BELCHER, A. M.; SUAREZ, L.; et al. Associations between psychological constructs and cardiac biomarkers following acute coronary syndrome. Psychosomatic medicine, v. 79, n. 3, p. 318, 2017. Doi: 10.1097/PSY.0000000000000404. Disponível

em: https://www.ncbi.nlm.nih.gov/pubmed/27749683.

CENK, E. R.; MAHMUT, O. K. Levels of cardiac biomarkers and coagulation profiles in dogs with parvoviral enteritis. Kafkas Universitesi Veteriner Fakultesi Dergisi, v. 21 n. 3 , p. 383-388, May/Jun 2015. Disponivel em: https://scholar.google.com/scholar?um=1\&ie=UTF8\&Ir\&cites=15459471489945637636 
CHANG, A. Y.; ABDULLAH, S. M.; JAIN, T.; STANEK, H. G.; DAS, S. R.; et al. Associations among androgens, estrogens, and natriuretic peptides in young women: observations from the Dallas Heart Study. Journal of the American College of Cardiology, v. 49, n. 1, p. 109-116, 2007. DOI: 10.1016/j.jacc.2006.10.040. Disponivel em: https://www.ncbi.nlm.nih.gov/pubmed/17207730.

CHOW, S. L.; MAISEL, A. S.; ANAND, I.; BOZKURT, B.; BOER, R. A.; et al. Role of biomarkers for the prevention, assessment, and management of heart failure: a scientific statement from the American Heart Association. Circulation, v. 135, n. 22, p. 1054-1091, 2017. DOI: doi.org/10.1161/CIR.0000000000000490. Disponível em: $<$ https://www.ahajournals.org/doi/pdf/10.1161/CIR.0000000000000490>.

CONNOLLY, D. J.; MAGALHAES, R. J.; SYME, H. M.; BOSWOOD, A.; FUENTES, V. L.; et al. Circulating natriuretic peptides in cats with heart disease. Journal of veterinary internal medicine, v. 22, n. 1, p. 96-105, 2008. doi: 10.1111/j.19391676.2007.0024.x. Disponivel em: https://www.ncbi.nlm.nih.gov/pubmed/18289295.

CONNOLLY, D. J.; BRODBELT, D. C.; COPELAND, H.; COLLINS, S.; FUENTES, V. L. Assessment of the diagnostic accuracy of circulating cardiac troponin I concentration to distinguish between cats with cardiac and non-cardiac causes of respiratory distress. Journal of Veterinary Cardiology, v. 11, n. 2, p. 71-78, 2009. Doi: 10.1016/j.jvc.2009.09.002. Disponível em: https://www.ncbi.nlm.nih.gov/pubmed/19879824.

COUTO, K. M.; IAZBIK, M. C.; MARÍN, L. M.; ZALDIVAR-LÓPEZ, S.; BEAL, M. J.; et

al. Plasma N-terminal pro-B-type natriuretic peptide concentration in healthy retired

racing Greyhounds. Veterinary clinical pathology, v. 44, n. 3, p. 405-409, 2015. Doi: 10.1111/vcp.12266. Disponível em: https://www.ncbi.nlm.nih.gov/pubmed/25982692.

DANIELS, L. B.; MAISEL, A. S. Cardiovascular biomarkers and sex: The case for women. Nat Rev Cardiol, n. 12, v. 10, p. 588-596, oct/2015. Doi: 10.1038/nrcardio.2015.105. Disponível em: https://www.ncbi.nlm.nih.gov/pubmed/26149486.

DEL RY, S.; CABIATI, M.; CLERICO, A. Natriuretic peptide system and the heart. Cardiovascular Issues in Endocrinology. Karger Publishers, v. 43, p. 134143, 2014. Disponível em: https://doi.org/10.1159/000360597.

FERREIRA, F. S.; BARRETO, F. L.; FEBRES, A.; SILVEIRA, L. S.; CARVALHO, C. B. Cardiac markers in five different breeds of rabbits (Oryctolagus cuniculus Linnaeus, 1758) used for cardiovascular research. Pesquisa Veterinária Brasileira, v. 36, n. 8, p. 737-742, 2016. DOI: 10.1590/S0100-736X2016000800010. Disponível em: http://www.scielo.br/pdf/pvb/v36n8/1678-5150-pvb-36-08-00737.pdf. 
FOX, P. R.; OYAMA, M. A.; HEZZELL, M. J.; RUSH, J. E.; NGUYENBA, T. P.; et al.

Relationship of plasma $\mathrm{N}$-terminal pro-brain natriuretic peptide concentrations to

heart failure classification and cause of respiratory distress in dogs using a 2nd generation ELISA assay. Journal of veterinary internal medicine, v. 29, n. 1, p. 171-179, 2015. Doi: 10.1111/jvim.12472. Dísponível em: https://www.ncbi.nlm.nih.gov/pubmed/25308881.

FREITAS, M. V.; FERREIRA, F. S.; BARRETTO, F. L.; CORREA, E. S.; CARVALHO, C. B. Creatinephosphokinase isoenzyme-MB mass (CK-MB MASS) and troponin I (cTnl) in dogs (Canisfamiliaris). Ciência Animal Brasileira, v. 16, n. 3, p. 369-376, 2015. ISSN 1809-6891. Doi: doi.org/10.1590/1089-6891v16i317474. Disponível em: http://www.scielo.br/scielo.php?pid=S180968912015000300369\&script=sci_abstract\&tlng=pt.

GALLAY-LEPOUTRE, J.; BELANGER, M. C.; NADEAU, M. E. Prospective evaluation of Doppler echocardiography, tissue Doppler imaging and biomarkers measurement for the detection of doxorubicin-induced cardiotoxicity in dogs: A pilot study. Research in veterinary science, v. 105, p. 153-159, 2016. Doi: 10.1016/j.rvsc.2016.02.001. Disponível em: https://www.ncbi.nlm.nih.gov/pubmed/27033925.

GARG, P.; MORRIS, P.; FAZLANIE, A. L.; VIJAYAN, S.; DANCSO, B.; et al. Cardiac biomarkers of acute coronary syndrome: from history to high-sensitivity cardiac troponin. Internal and emergency medicine, v. 12, n. 2, p. 147-155, 2017. Doi: 10.1007/s11739-017-1612-1. https://www.ncbi.nlm.nih.gov/pubmed/28188579.

HARRIS, A. N.; ESTRADA, A. H.; GALLAGHER, A. E.; WINTER, B.; LAMB, K. E.; et al. Biologic variability of $\mathrm{N}$-terminal pro-brain natriuretic peptide in adult healthy cats. Journal of feline medicine and surgery, v. 19, n. 2, p. 216-223, 2017. Doi: 10.1177/1098612X15623825. https://www.ncbi.nlm.nih.gov/pubmed/26767980.

HARIU, C. D.; SAUNDERS, A. B.; GORDON, S. G.; NORBY, B.; MILLER, M. W. Utility of $\mathrm{N}$-terminal pro-brain natriuretic peptide for assessing hemodynamic significance of patent ductus arteriosus in dogs undergoing ductal repair. Journal of veterinary cardiology, v. 15, n. 3, p. 197-204, 2013. Doi: 10.1016/j.jvc.2013.02.006. Disponível em: https://www.ncbi.nlm.nih.gov/pubmed/23933478.

HEISHIMA, Y.; HORI, Y. NAKAMURA, K.; YAMASHITA, Y.; ISAYAMA, N.; et al. Diagnostic accuracy of plasma atrial natriuretic peptide concentrations in cats with and without cardiomyopathies. Journal of Veterinary Cardiology, v. 20, n. 4, p. 234-243, 2018. Doi: 10.1016/j.jvc.2018.04.008. Disponível em: https://www.ncbi.nlm.nih.gov/pubmed/29807749. 
HEZZELL, M. J.; BOSWOOD, A.; LOTTER, N.; ELLIOTT, J. The effects of storage conditions on measurements of canine $\mathrm{N}$-terminal pro-B-type natriuretic peptide. Journal of Veterinary Cardiology, v. 17, n. 1, p. 34-41, 2015. Doi: 10.1016/j.jvc.2014.10.002. Disponível

em: https://www.ncbi.nlm.nih.gov/pubmed/25547663.

HORI, Y.; YAMANO, S.; KANAI, K.; HOSHI, F.; ITOH, N.; et al. Clinical implications of measurement of plasma atrial natriuretic peptide concentration in dogs with spontaneous heart disease. Journal of the American Veterinary Medical Association, v. 239, n. 8, p. 1077-1083, 2011. Doi: 10.2460/javma.239.8.1077. Disponível em: https://www.ncbi.nlm.nih.gov/pubmed/21985348.

HORI, Y.; IGUCHI, M.; HEISHIMA, Y.; YAMASHITA, Y.; NAKAMURA, K.; et al. Diagnostic utility of cardiac troponin $I$ in cats with hypertrophic cardiomyopathy. Journal of veterinary internal medicine, v. 32, n. 3, p. 922-929, 2018. Doi: 10.1111/jvim.15131. Disponível em: https://www.ncbi.nlm.nih.gov/pmc/articles/PMC5980312/.

IDEXX LABORATORIES. Interpretive Criteria for the Canine Cardiopet@ proBNP Test. 2013. Disponível em: <https://www.idexx.com.br/pt$\mathrm{br} /$ veterinary/support/documents-resources/reference-laboratories-resources/>.

KANNO, N.; HORI, Y.; HIDAKA, Y.; CHIKAZAWA, S.; KANAI, K.; HOSHI, F.; ITOH, $\mathrm{N}$. Plasma atrial natriuretic peptide and $\mathrm{N}$-terminal pro B-type natriuretic peptide concentrations in dogs with right-sided congestive heart failure. Journal of Veterinary Medical Science, v. 78, n. 4, p. 535-542, Apr 2016. Doi: 10.1292/jvms.15-0435. Disponível

em: https://www.ncbi.nlm.nih.gov/pubmed/26607133.

KATUS, H. A.; REMPPIS, A.; SCHEFFOLD, T.; DIEDERICH, K. W.; KUEBLER, W. Intracellular compartmentation of cardiac troponin $\mathrm{T}$ and its release kinetics in patients with reperfused and nonreperfused myocardial infarction. The American journal of cardiology, v. 67, n. 16, p. 1360-1367, 1991. Disponível em: https://www.ncbi.nlm.nih.gov/pubmed/1904190.

KISHIMOTO, I.; MAKINO, H.; OHATA, Y.; TAMANAHA, T.; TOCHIYA, M.; et al. Impact of B-type natriuretic peptide (BNP) on development of atrial fibrillation in people with Type 2 diabetes. Diabetic Medicine, v. 33, n. 8, p. 1118-1124, 2015. Doi: 10.1111/dme.12856. Disponivel em: https://www.ncbi.nlm.nih.gov/pubmed/26173591.

KLÜSER, L.; HOLLER, P. J.; SIMAK, J.; TATER, G.; SMETS, P.; et al. Predictors of Sudden cardiac death in doberman pinschers with dilated cardiomyopathy. Journal of Veterinary Internal Medicine, v. 30, n. 3. p. 722-732, May 2016. Doi: 10.1111/jvim.13941. Disponível em: https://www.ncbi.nlm.nih.gov/pubmed/27177626.

KOBAYASHI, K.; HORI, Y.; CHIMURA, S. Plasma N-terminal pro B-type natriuretic peptide concentrations in dogs with pulmonic stenosis. Journal of Veterinary 
Medical Science, v. 76, n. 6, p. 827-831, 2014. Doi: 10.1292/jvms.13-0554. Disponível: https://www.ncbi.nlm.nih.gov/pmc/articles/PMC4108765/.

KÖSTER, L. S.; LOBETTI, R. G.; KELLY, P. Canine babesiosis: a perspective on clinical complications, biomarkers, and treatment. Veterinary medicine: research and reports, v. 6, p. 119, 2015. Doi: 10.2147/VMRR.S60431. Disponível em: https://www.ncbi.nlm.nih.gov/pmc/articles/PMC6065580/.

LANGHORN, R.; WILLESEN, J. L. Cardiac troponins in dogs and cats. Journal of veterinary internal medicine, v. 30, n. 1, p. 36-50, 2016. Doi: 10.1111/jvim.13801 Disponível em: <https://onlinelibrary.wiley.com/doi/epdf/10.1111/jvim.13801>.

LANGHORN, R.; TARNOW, I.; WILLESEN, J. L.; KJELGAARD-HANSEN, M.; SKOVGAARD, I. M.; KOCH, J. Cardiac troponin I and T as prognostic markers in cats with hypertrophic cardiomyopathy. Journal of veterinary internal medicine, $\mathrm{v}$. 28, n. 5, p. 1485-1491, 2014. Doi: 10.1111/jvim.12407. Disponível em: https://www.ncbi.nlm.nih.gov/pubmed/25056593.

LEE, G.; TWERENBOLD, R.; TANGLAY, Y.; REICHLIN, T.; HONEGGER, U.; et al. Clinical benefit of high-sensitivity cardiac troponin I in the detection of exerciseinduced myocardial ischemia. American heart journal, v. 173, p. 8-17, 2016. DOI: 10.1016/j.ahj.2015.11.010.

Disponível

em: https://europepmc.org/abstract/med/26920591.

LIMA, G. V.; FERREIRA, F. S. N-terminal-pro brain natriuretic peptides in dogs and cats: A technical and clinical review. Veterinary world, v. 10, n. 9, p. 1072, 2017. Doi: 10.14202/vetworld.2017.1072-1082. Disponível em: https://www.ncbi.nlm.nih.gov/pmc/articles/PMC5639106/.

MACHEN, M. C.; OYAMA, M. A.; GORDON, S. G.; RUSH, J. E.; ACHEN, S. E.; et al. Multi-centered investigation of a point-of-care NT-proBNP ELISA assay to detect moderate to severe occult (pre-clinical) feline heart disease in cats referred for cardiac evaluation. Journal of Veterinary Cardiology, v. 16, n. 4, p. 245-255, 2014. Doi: 10.1016/j.jvc.2014.09.002. Disponível em: https://www.ncbi.nlm.nih.gov/pubmed/25456274.

MATTIN, M. J.; BOSWOOD, A.; CHURCH, D. B.; BRODBOLT, D. C. Prognostic factors in dogs with presumed degenerative mitral valve disease attending

primary-care veterinary practices in the United Kingdom. Journal of Veterinary

Internal Medicine, 2018. Disponível em: <https://doi.org/10.1111/jvim.15251>.

MENAUT, P.; CONNOLLY, D. J.; VOLK, A.; PACE, C.; LUIS FUENTES, V.; et al. Circulating natriuretic peptide concentrations in hyperthyroid cats. Journal of Small Animal Practice, v. 53, n. 12, p. 673-678, 2012. Disponível em: https://doi.org/10.1111/j.1748-5827.2012.01301.x. 
MILLER, W. L.; JAFFE, A. S. Biomarkers in heart failure: The importance of inconvenient details. ESC Heart Failure, v. 3, n.1, p. 3-10, Mar 2016. DOI: 10.1002/ehf2.12071. Disponível https://onlinelibrary.wiley.com/doi/full/10.1002/ehf2.12071.

MILNE, E. M.; DOXEY, D. L. Lactate dehydrogenase and its isoenzymes in the tissues and sera of clinically normal dogs. Research in veterinary science, v. $43, n$. 2, p. 222-224, 1987. Disponível em: https://www.ncbi.nlm.nih.gov/pubmed/3685636.

OYAMA, M. A. Using cardiac biomarkers in veterinary practice. Clinics in laboratory medicine, v. $35, \quad$ n. 3 , p. 555-566, $2015 . \quad$ DOI: https://doi.org/10.1016/j.cll.2015.05.005. Disponível em <https://www.labmed.theclinics.com/article/S0272-2712(15)00047-5/pdf>.

OYAMA, M. A.; SISSON, D. D. Cardiac troponin-I concentration in dogs with cardiac disease. Journal Veterinary Internal Medicine, v. 18, n. 6, p. 831-9, Nov/Dec 2004. ISSN 0891-6640. Disponível em: https://www.ncbi.nlm.nih.gov/pubmed/15638266.

PARIKH, R. H.; SELIGER, S. L.; DEFILIPPI, C. R. Use and interpretation of high sensitivity cardiac troponins in patients with chronic kidney disease with and without acute myocardial infarction. Clinical Biochemistry, v. 48, n. 4-5, p. 247-253, Mar/ 2015. DOI: 10.1016/j.clinbiochem.2015.01.004. Disponivel em: https://www.ncbi.nlm.nih.gov/pubmed/25617663.

PELANDER, L.; HÄGGSTRÖM, J.; LEY, C. J; LJUNGVALL, I. Cardiac Troponin I and Amino-Terminal Pro B-Type Natriuretic Peptide in Dogs With Stable Chronic Kidney Disease. Journal Veterinary Internal Medicine, v. 31, n. 3, p. 805-813, May/2017. Doi: 10.1111/jvim.14703. Disponível em: https://www.ncbi.nlm.nih.gov/pubmed/28370332.

PINO, V. O.; LI, E. O.; ALVARADO, S. A.; FERNÁNDEZ, P. V.; DÁVILA, F. R.; GAVIDIA, CH. C. Determinación de los niveles séricos de enzimas cardíacas en perros adultos con enfermedad cardiovascular. Revista de Investigaciones Veterinarias del Peru, v. 19, n. 2, p. 144-147, 2008. Disponível em: http://www.scielo.org.pe/scielo.php?script=sci_arttext\&pid=S1609-

91172008000200006.

POLIZOPOULOU, Z. S.; KOUTINAS, C. K.; DASOPOULOU, A.; PATSIKAS, M.; YORK, M.; et al. Serial analysis of serum cardiac troponin I changes and correlation with clinical findings in 46 dogs with mitral valve disease. Veterinary clinical pathology, v. 43, n. 2, p. 218-225, 2014. Doi: 10.1111/vcp.12124. Dispovinel em: https://www.ncbi.nlm.nih.gov/pubmed/24612252.

PROSEK, R.; ETTINGER, S. Biomarkers of cardiovascular disease. In: ETTINGER, S. e FELDMAN, E. (Ed.). Veterinary Internal Medicine: diseases of the dog and cat. St. Louis: Saunders Elsevier, cap. 1187-1196. 2010.

REIMANN, M. J.; LJUNGVALL, I.; HILLSTRÖM, A.; MØLLER, J. E.; HAGMAN, R.; et al. Increased serum $\mathrm{C}$-reactive protein concentrations in dogs with congestive heart 
failure due to myxomatous mitral valve disease. The Veterinary Journal, v. 209, p. 113-118, 2016. Disponível em: < https://doi.org/10.1016/j.tvjl.2015.12.006>.

RUAUX, C.; SCOLLAN, K.; SUCHODOLSKI, J. S.; STEINER, J. M.; SISSON, D.

Biologic variability in NT-pro BNP and cardiac troponin-I in healthy dogs and dogs

with mitral valve degeneration. Veterinary clinical pathology, v. 44, n. 3, p. 420430, 2015. Doi: 10.1111/vcp.12268. Dispinível em: https://www.ncbi.nlm.nih.gov/pubmed/26108974.

SHARP, C. R.; ROZANSKI, E. A. Cardiovascular and systemic effects of gastric dilatation and volvulus in dogs. Topics in companion animal medicine, v. 29, n. 3, p. 67-70, 2014. Doi: 10.1053/j.tcam.2014.09.007. Disponível em: https://www.ncbi.nlm.nih.gov/pubmed/25496923.

SHIELDS, E.; SEIDEN-LONG, I.; MASSIE, S.; PASSANTE, S.; LEGUILLETTE, R. Analytical validation and establishment of reference intervals for a "highsensitivity'cardiac troponin-T assay in horses. BMC veterinary research, v. 12, n. 1, p. 104, 2016. Disponível em: https://doi.org/10.1186/s12917-016-0737-1

SCHOBER, K. Biochemical markers of cardiovascular disease. In: ETTINGER, S.; FELDMAN, E. (Ed.). Textbook of veterinary internal medicine. 2. St. Louis: Elsevier Saunders, 2010. p.940-994

SINGLETARY, G. E.; MORRIS, N. A.; O'SULLIVAN, M. L; GORDON, S. G.; OYAMA,

M. A. Prospective Evaluation of NT-pro BNP Assay to Detect Occult Dilated

Cardiomyopathy and Predict Survival in D oberman Pinschers. Journal of veterinary internal medicine, v. 26, n. 6, p. 1330-1336, 2012. Doi: 10.1111/j.19391676.2012.1000.x. Disponível em: https://www.ncbi.nlm.nih.gov/pubmed/22998090.

SMITH, K. F.; QUINN, R. L.; RAHILLY, L. J. Biomarkers for differentiation of causes of respiratory distress in dogs and cats: Part 2-lower airway, thromboembolic, and inflammatory diseases. Journal of Veterinary Emergency and Critical Care, v. 25, n. 3, p. 330-348, May-Jun 2015a. Doi: 10.1111/vec.12317. Disponivel em: https://www.ncbi.nlm.nih.gov/pubmed/26040815.

SMITH, K. F.; QUINN, R. L.; RAHILLY, L. J. Biomarkers for differentiation of causes of respiratory distress in dogs and cats: Part 1-cardiac diseases and pulmonary hypertension. Journal of Veterinary Emergency and Critical Care, v. 25, n. 3, p. 311-329, May-Jun 2015b. Doi: 10.1111/vec.12318. Disponivel em: https://www.ncbi.nlm.nih.gov/pubmed/26040814. 
SOLTER, P. F.; OYAMA, M. A.; MACHEN, M. C.; TRAFNY, D. J.; SISSON, D. D. Detection by ELISA of C-terminal proBNP in plasma from cats with cardiomyopathy. The Veterinary Journal, v. 206, n. 2, p. 213-217, 2015. DOI: 10.1016/j.tvjl.2015.07.015.

em: https://europepmc.org/abstract/med/26324638.

STEVENSON, C. K.; KIDNEY, B. A.; DUKE, T.; SNEAD, E. C.; MAINAR-JAIME, R. C.; JACKSON, M. L. Serial blood lactate concentrations in systemically ill dogs. Veterinary clinical pathology, v. 36, n. 3, p. 234-239, 2007. Disponível em: https://www.ncbi.nlm.nih.gov/pubmed/17806070.

WESS, G.; HABIL, D.; DOMENECH, O.; DUKES-MCEWAN, J.; HÄGGSTRÖM, J.; GORDON, S.; European Society of Veterinary Cardiology screening guidelines for dilated cardiomyopathy in Doberman Pinschers. Journal of Veterinary Cardiology, v. 19, n. 5, p, 405-415, Oct 2017. Doi: 10.1016/j.jvc.2017.08.006. Disponivel em: https://www.ncbi.nlm.nih.gov/pubmed/28965673.

WESS, G.; SIMAK, J.; MAHLING, M.; HARTMANN, K. Cardiac troponin I in Doberman Pinschers with cardiomyopathy. Journal of veterinary internal medicine, v. 24, n. 4, p. 843-849, 2010. Disponível em: https://doi.org/10.1111/j.1939-1676.2010.0516.x.

WINTER, R. L.; SOUNDERS, A. B.; GORDON, S. G.; BUCH, J. S.; MILLER, M. W. Biologic variability of $\mathrm{N}$-terminal pro-brain natriuretic peptide in healthy dogs and dogs with myxomatous mitral valve disease. Journal of veterinary cardiology, $v$. 19, n. 2, p. 124-131, 2017. Disponível em: < https://doi.org/10.1016/j.jvc.2016.11.001>.

WOLF, J.; GERLACH, N.; WEBER, K.; KLIMA, A.; WESS, G. The diagnostic relevance of NT-pro BNP and pro ANP 31-67 measurements in staging of myxomatous mitral valve disease in dogs. Veterinary clinical pathology, v. 42, n. 2, p. 196-206, 2013. Doi: 10.1111/vcp.12044. Disponível em: https://www.ncbi.nlm.nih.gov/pubmed/23614733. 